\title{
Addressing Health-Related Social Needs: Value-Based Care or Values-Based Care?
}

\author{
Seth A. Berkowitz' , Travis P. Baggett ${ }^{2,3}$, and Samuel T. Edwards ${ }^{4,5}$ \\ 'Division of General Medicine and Clinical Epidemiology, Department of Medicine, University of North Carolina School of Medicine, Chapel Hill, \\ NC, USA; ${ }^{2}$ Division of General Internal Medicine, Massachusetts General Hospital, Boston, MA, USA; ${ }^{3}$ Boston Health Care for the Homeless Program , \\ Institute for Research, Quality, and Policy in Homeless Health Care, Boston, MA, USA; ${ }^{4}$ Section of General Internal Medicine , Veterans Affairs (VA) \\ Portland Health Care System, Portland, OR, USA; ${ }^{5}$ Division of General Internal Medicine and Geriatrics, Oregon Health \& Science University, \\ Portland, OR, USA.
}

Health-related social needs, such as food insecurity, housing instability, and lack of transportation, are associated with worse health outcomes, and are increasingly the focus of health-related social needs interventions within healthcare. Adoption of health-related social needs interventions is often justified by the potential to reduce healthcare costs. However, this can present a conundrum to clinicians. Physicians are often more accustomed to justifying clinical innovation based on improvements in health, in accord with the fundamental values of the medical profession, which include using our knowledge, skills, and the resources at our disposal to improve both individual and public health. In cases where health-related social needs interventions improve health but are not cost-saving, these two types of justifications can conflict. We provide a framework for considering these issues, and an agenda for scholarly work on this topic. Ultimately, if promoting patient and public health are key values for our profession, then understanding when to emphasize values-based care, rather than simply value-based care, is crucial to fulfilling our professional duty.

KEY WORDS: social determinants of health; value-based care; socioeconomic factors; population health management; food insecurity.

J Gen Intern Med 34(9):1916-8

DOI: $10.1007 / \mathrm{s} 11606-019-05087-3$

(c) Society of General Internal Medicine 2019

$\mathrm{H}$ ealth-related social needs, such as food insecurity, housing instability, and lack of transportation, are associated with higher disease prevalence, worse control of chronic conditions, increased stress and depressive symptoms, and lower quality of life. ${ }^{1-6}$ Perhaps for these reasons, individuals with health-related social needs often have adverse patterns of healthcare utilization, including more frequent inpatient admissions and emergency department visits, and greater healthcare costs. ${ }^{1,2,6,7}$

Received March 1, 2019

Revised March 29, 2019

Accepted April 25, 2019

Published online June 10, 2019
To address these issues, healthcare-based interventions for health-related social needs are becoming more common, as illustrated by the Accountable Health Communities Pilot, ${ }^{6} 1115$ Medicaid waivers in North Carolina ${ }^{8}$ and other states, and internal programs within many healthcare organizations. Example interventions include navigating patients to resources such as food pantries, deploying community health workers, providing tenancy support services, and arranging transportation to medical appointments. Though the field is still developing, these interventions are seeing widespread and enthusiastic deployment. This has brought urgency to the need to consider the justification for such interventions, and to the need to make hard choices about allocating scarce resources.

The justification for health-related social needs interventions often takes one of two forms. ${ }^{9}$ The health-oriented justification argues for health-related social needs interventions because they improve health. Fundamentally, the healthoriented justification draws upon the values of the medical profession, which include the primacy of patient welfare, recognizing the autonomy of individuals, and our duty to use the knowledge, skills, and resources at our disposal to improve both individual and public health.

The market-oriented justification draws upon the view that healthcare systems need to reduce healthcare costs, which are burdensome to society. In this justification, health-related social needs interventions can produce "return on investment" (e.g., cost savings) resulting from lower use of healthcare services once needs are met.

The medical profession has classically used the healthoriented justification when deciding whether to adopt innovations in care practices (although profit motives have, of course, been drivers for firms to develop new treatments). In contrast, the justification for health-related social needs interventions has largely been market-oriented. ${ }^{6,8-10}$ Some of this may be due to contemporary trends - particularly neoliberal approaches to healthcare cost containment ${ }^{11,12}$ and the ethos of value-based care, which emphasizes the efficient use of resources as a guiding principle for allocating healthcare, and draws upon examples from free-market enterprise to achieve its goals. $^{13}$ 
The market-oriented justification often fosters interventions that target "superutilizers" - those who are at increased risk of accruing high healthcare expenditures due to a combination of morbidity and social need. ${ }^{9}$ Because these individuals also face high risk for poor health outcomes, both a health-oriented and a market-oriented justification can apply. Hence, even clinicians who favor a health-orientated justification may follow a marketoriented justification, viewing it as the path of least resistance for obtaining institutional approval, and funding, for their work.

Healthcare professionals should be wary of over-reliance on market-oriented justifications, however. First, doing so equates deservingness of intervention with the likelihood of generating high healthcare costs. But if our professional values are to promote the health of our patients, it is difficult to see why individuals with health-related social needs should be treated only if the short-term cost of not doing so is high. Health-related social needs that impact early childhood development (for example, poor housing conditions leading to lead exposure) and preventive care (for example, lack of transportation to attend breast cancer screening) can have a profound effect on future health (cognitive impairment and cancer mortality, respectively), but little chance of affecting short-term healthcare costs.

Second, though health-related social needs interventions can be cost-saving, ${ }^{14}$ there are likely many situations where they are not, as most healthcare is not cost-saving. Further, there is no sector of American healthcare that routinely applies even a cost-effectiveness, much less a cost-saving, criterion to adoption of medical innovation. While the wisdom of that approach is up for debate, why hold health-related social needs interventions to a different standard?

These considerations lead to several core questions that future scholarly work around health-related social needs should address:

1. How should we decide when to apply health-oriented justifications versus market-oriented justifications? If they are in conflict, do we choose values-based care or value-based care? More broadly, when should we adopt healthcare innovation simply because it improves health, and when should additional justification be required? Can reflection on the values of our profession, and affirming those values when making difficult decisions about what innovations in care to adopt, help us practice the type of medicine we aspire to ${ }^{15}$

2. How should we evaluate interventions that target healthrelated social needs? Health-related social needs interventions plausibly affect multiple dimensions of health, often through complex pathways. This means we may need both better outcome measure and more sophisticated methods to understand their effects. Measuring prevention of clinical events, such as asthma exacerbations in those with poorquality housing, or well-established biomarkers, such as hemoglobin A1c levels in those with diabetes and food insecurity, is straight-forward. However, these may not fully capture the benefit of health-related social needs interventions - patient-reported outcomes will be key for understanding the effects of these programs. Doing this may require developing new measures that assess constructs most relevant for those with health-related social needs, analogous to the need for condition-specific symptom scales in cancer treatment or joint replacement surgery. Further, beyond the outcome measures issue, interventions that address health-related social needs are complex, have multiple components, and may involve both clinical and non-clinical personnel. Evaluations may therefore require sophisticated methods, often with both qualitative and quantitative components, that can better assess why and how interventions work, and what contextual elements, adaptations, and implementation strategies are necessary for success. ${ }^{16}$

3. What is the value - including costs, benefits, and harms — of health-related social needs interventions? What are the circumstances under which health-related social needs interventions are cost-saving, cost-effective, or neither? Further, what are the timescales at which to evaluate these interventions? If cost savings only accrue over a long timehorizon, how should investment in health-related social needs interventions be encouraged or sustained? For other areas of scientific investigation, cost analyses may occur once effectiveness has been established. Should healthrelated social needs interventions be different?

Health-related social needs interventions offer great potential for improving care in vulnerable populations, and we are in an exciting time of scientific discovery regarding their use. In cases where these interventions improve health and reduce costs, their adoption should be uncontroversial. Likewise, in situations where they offer no benefit, our efforts are best spent elsewhere. But what to do in situations where health-related social needs interventions improve health, but are not costsaving, remains unclear. As a field, we will need to work to clarify what justifications for health-related social needs interventions are relevant in particular circumstances. Ultimately, if promoting patient and public health are key values for our profession, then understanding when to emphasize valuesbased care, rather than simply value-based care, is crucial to fulfilling our professional duty.

Acknowledgments: We would like to thank Fleming et al., the authors of reference number 9, for providing a helpful vocabulary for discussing these topics, which we drew from in this manuscript.

Corresponding Author: Seth A. Berkowitz, Division of General Medicine and Clinical Epidemiology, Department of Medicine University of North Carolina School of Medicine, 5034 Old Clinic Bldg, CB 7110, Chapel Hill, NC 27599, USA (e-mail: seth_berkowitz@med.unc. edu).

Funding Information $S A B$ role in this manuscript was financially supported by the National Institute of Diabetes And Digestive And Kidney Diseases of the National Institutes of Health under Award Number K23DK109200. 


\section{Compliance with Ethical Standards:}

Conflict of Interest: Dr. Baggett receives royalties from UpToDate for authorship of a topic review on healthcare for people experiencing homelessness. All remaining authors declare that they do not have a conflict of interest.

Disclaimer: The content is solely the responsibility of the authors and does not necessarily represent the official views of the National Institutes of Health or the Department of Veterans Affairs.

\section{REFERENCES}

1. Committee on the Recommended Social and Behavioral Domains and Measures for Electronic Health Records, Board on Population Health and Public Health Practice, Institute of Medicine. Capturing Social and Behavioral Domains and Measures in Electronic Health Records: Phase 2. Washington (DC): National Academies Press (US); 2015. http://www. ncbi.nlm.nih.gov/books/NBK268995/. Accessed March 29, 2019.

2. Gottlieb L, Tobey R, Cantor J, Hessler D, Adler NE. Integrating Social And Medical Data To Improve Population Health: Opportunities And Barriers. Health Aff Proj Hope 2016;35(11):2116-2123. https://doi.org/ 10.1377/hlthaff.2016.0723

3. Seligman HK, Laraia BA, Kushel MB. Food insecurity is associated with chronic disease among low-income NHANES participants. J Nutr 2010; 140(2):304-310. https://doi.org/10.3945/jn.109.112573

4. Silverman J, Krieger J, Kiefer M, Hebert P, Robinson J, Nelson $\mathbf{K}$. The Relationship Between Food Insecurity and Depression, Diabetes Distress and Medication Adherence Among Low-Income Patients with PoorlyControlled Diabetes. J Gen Intern Med 2015;30(10):1476-1480. https:// doi.org/10.1007/s11606-015-3351-1

5. Njai R, Siegel P, Yin S, Liao Y. Prevalence of Perceived Food and Housing Security - 15 States, 2013. MMWR Morb Mortal Wkly Rep 2017;66(1):12_ 15. https://doi.org/10.15585/mmwr.mm6601a2

6. Alley DE, Asomugha CN, Conway PH, Sanghavi DM. Accountable Health Communities-Addressing Social Needs through Medicare and Medicaid. N Engl J Med 2016;374(1):8-11. https://doi.org/10.1056/ NEJMp1512532
7. Berkowitz SA, Seligman HK, Meigs JB, Basu S. Food insecurity, healthcare utilization, and high cost: a longitudinal cohort study. Am J Manag Care 2018;24(9):399-404.

8. Verma S. CMS Approves North Carolina's Innovative Medicaid Demonstration To Help Improve Health Outcomes. https://www.healthaffairs. org/do/10.1377/hblog20181024.406020/full/. Accessed October 30, 2018.

9. Fleming MD, Shim JK, Yen I, Van Natta M, Hanssmann C, Burke NJ. Caring for "Super-utilizers": Neoliberal Social Assistance in the Safetynet. Med Anthropol Q 2018. https://doi.org/10.1111/maq.12481

10. In Depth: Payers can't control costs without social determinants of health model. Mod Healthc https://www.modernhealthcare.com/article/ 20180825/NEWS/180829956/in-depth-payers-can-t-control-costswithout-social-determinants-of-health-model. Published August 22, 2018. Accessed March 29, 2019.

11. Dranove D, Ody C, Starc A. A Dose of Managed Care: Controlling Drug Spending in Medicaid. National Bureau of Economic Research; 2017. https://doi.org/10.3386/w23956

12. Neuman P, Jacobson GA. Medicare Advantage Checkup. N Engl J Med 2018;379(22):2163-2172. https://doi.org/10.1056/NEJMhpr1804089

13. What is value-based healthcare? NEJM Catalyst. https://catalyst.nejm. org/what-is-value-based-healthcare/. Published January 1, 2017. Accessed March 29, 2019.

14. Berkowitz SA, Terranova J, Hill C, et al. Meal Delivery Programs Reduce The Use Of Costly Health Care In Dually Eligible Medicare And Medicaid Beneficiaries. Health Aff Proj Hope 2018;37(4):535-542. https://doi.org/ 10.1377/hlthaff.2017.0999

15. Cooper LA, Barnes D. Journey to eliminating health care disparities: the urgency of affirming values within our patients, profession, health care system, and society. Arch Intern Med 2012;172(21):1667-1669. https:// doi.org/10.1001/2013.jamainternmed.266

16. PCORI Methodology Standards: Standards for Studies of Complex Interventions. https://www.pcori.org/research-results/about-our-research/research-methodology/pcori-methodology-standards\#Complex. Published November 12, 2015. Accessed March 29, 2019.

Publisher's Note: Springer Nature remains neutral with regard to jurisdictional claims in published maps and institutional affiliations. 